\title{
Anisotropy of fracture toughness of 2124 aluminum alloy plates
}

\author{
JIAN Haigen ${ }^{1, a}$, LUO Jian ${ }^{1, b}$, LIU Zheng ${ }^{2, c}{ }^{*}$ and TANG Xianmin ${ }^{1, d}$ \\ ${ }^{1}$ School of Metallurgical Engineering, Hunan University of Technology, Zhuzhou, 412007, China \\ 2Jiangsu Agri-animal Husbandry Vocational College, Taizhou, 225300, China \\ ajianhaigen2001@163.com, b2209737785@qq.com, '840225961@qq.com, \\ d1109754661@qq.com \\ *840225961@qq.com
}

Keywords: 2124 Aluminum Alloy, Fracture Toughness, Anisotropy, Size Effect

Abstract. The plane strain fracture toughness $\mathrm{K}_{\mathrm{IC}}$ values of 2124 aluminum alloy plate of T-L and L-T orientation of thickness of $30 \mathrm{~mm}, 40 \mathrm{~mm}$, and $50 \mathrm{~mm}$ were tested by using the standard compact tension specimen. The $\mathrm{K}_{\mathrm{IC}}$ anisotropic degree and mechanism of different thickness of 2124 aluminum alloy were studied through analyzing fracture morphology by scanning electron microscopy (SEM). The results indicate that the anisotropy of 2124 aluminum alloy plate is obvious, the differences between fracture toughness $\mathrm{K}_{\mathrm{IC}}$ of different orientation with same thickness are evident, the $\mathrm{K}_{\mathrm{IC}}$ of L-T orientation is higher than T-L orientation about $4 \sim 9 \mathrm{MPa} \cdot \mathrm{m}^{1 / 2}$.

\section{Introduction}

On the basis of traditional 2024 aluminum alloy, 2124 aluminum alloy is the Al-Cu-Mg alloy which is developed to use in aviation by lowering the contents of impurities such as iron, silicon [1], the quality of this alloy is light, but its ductility and the damage resistance are high, the elongation and fracture toughness of thick plates are superior to the conventional 2024 alloy thick plates, and the short transverse performance is particularly prominent. Thick plates usually use in T351 and T851 state and are mainly used to manufacture structural parts that are heat resistant, corrosion resistant and stress durable in the aerospace field [2-3].

Fracture toughness has obvious directional differences, which is associated with the anisotropy of material. For some aluminum alloy, the anisotropic degree of fracture toughness is high; the differences between values of $\mathrm{K}_{\mathrm{IC}}$ can reach $60 \%$ with different fracture direction [4-5]. In recent years, deep researches in the aspects of composition, microstructure and the heat treatment process of 2124 aluminum alloy were carried out by many material workers [6-9]. But there is a little attention about anisotropy of fracture toughness of 2124 aluminum alloy plates and no study to analyze the reason and mechanism of anisotropy of fracture toughness of 2124 aluminum alloy plates in detail, especially in the aspect of effects of plate thickness to the fracture toughness.

In order to study the anisotropy of 2124-T851 aluminum alloy $\mathrm{K}_{\mathrm{IC}}$ values of aviation structure, hot rolling thick plates of different thickness were selected in this experiment, the $\mathrm{K}_{\mathrm{IC}}$ values of T-L orientation and L-T orientation were measured respectively, the anisotropic degree and mechanism of fracture toughness of 2124 aluminum alloy were analyzed.

\section{Experiment}

Research materials were provided by Northeast Light Alloy Co., LTD. of CHINALCO, three different thicknesses of 2124-T851 aluminum alloy plates were provided, and the thicknesses are $30 \mathrm{~mm}, 40 \mathrm{~mm}$ and $55 \mathrm{~mm}$ respectively. Alloy compositions are shown in table 1.

Different thickness of 2124 aluminum alloy plates are obtained after sawing, milling surface roughly and hot rolling, then two-stage aging treatment of $15{ }^{\circ} \mathrm{C} / 8 \mathrm{~h}+165^{\circ} \mathrm{C} /$ after heat preserving $60 \mathrm{~min}$ at $470{ }^{\circ} \mathrm{C}$ were carried out. According to the testing standard HB5142-96, 2124 aluminum alloy samples were drawn and processed into compact tensile samples. Before the experiment, the load was selected in the light of vertical and horizontal yield strength of 2124 aluminum alloy plates, the fatigue crack of 
$2 \mathrm{~mm}$ long was prefabricated, the fracture toughness tests along the orientation of rolling and transverse were carried out at MTS810-100 KN testing machine according to the standard HB5142-96.

Table 1 Chemistry composition of research alloy(mass fraction, \%)

\begin{tabular}{ccccccccc}
\hline $\mathrm{Cu}$ & $\mathrm{Mg}$ & $\mathrm{Mn}$ & $\mathrm{Fe}$ & $\mathrm{Si}$ & $\mathrm{Cr}$ & $\mathrm{Ti}$ & $\mathrm{Zn}$ & $\mathrm{Al}$ \\
\hline 4.22 & 1.40 & 0.56 & 0.20 & 0.12 & $<0.05$ & $<0.12$ & $<0.25$ & Bal. \\
\hline
\end{tabular}

Specimen for scanning tests were taken from $\mathrm{K}_{\mathrm{IC}}$ specimen fracture, fracture morphology characteristics of crack propagation region were observed under KYKY - 2800 scanning electron microscopy (SEM), the accelerating voltage is $20 \mathrm{KV}$.

\section{Results and Discussion}

The 2124-T851 alloy plates of different thickness of $30 \mathrm{~mm}, 40 \mathrm{~mm}$ and $55 \mathrm{~mm}$ were prepared for three specimens respectively with different orientation, the experimental results of plate fracture toughness were obtained by calculating the average values of experimental results, as are shown in table 2 .

Table 2 Experimental results of fracture toughness of 2214-T851 alloy $\left(\mathrm{MPa} \cdot \mathrm{m}^{1 / 2}\right)$

\begin{tabular}{cccccc}
\hline Plate thickness $/ \mathrm{mm}$ & Sample direction & $\mathrm{K}_{\mathrm{IC}-1}$ & $\mathrm{~K}_{\mathrm{IC}-2}$ & $\mathrm{~K}_{\mathrm{IC}-3}$ & $\mathrm{~K}_{\mathrm{IC}-\mathrm{AVG}}$ \\
\hline 30 & $L-T$ & 29.8 & 29.85 & 29.26 & 29.64 \\
& $T-L$ & 24.04 & 24.46 & 24.44 & 24.31 \\
40 & $L-T$ & 32.77 & 32.56 & 33.52 & 32.95 \\
& $T-L$ & 23.69 & 24.05 & 24.07 & 23.94 \\
55 & $L-T$ & 28.89 & 28.78 & 28.98 & 28.88 \\
& $T-L$ & 25.42 & 24.55 & 24.62 & 24.86 \\
\hline
\end{tabular}

As it can be seen from table 2, when the plate orientation is L-T, fracture toughness of thickness of $40 \mathrm{~mm}$ is best, thickness of $30 \mathrm{~mm}$ is moderate, thickness of $55 \mathrm{~mm}$ is worst. When the plate orientation is T-L, fracture toughness of thickness of $55 \mathrm{~mm}$ is best, thickness of $40 \mathrm{~mm}$ is worst, thickness of 30 $\mathrm{mm}$ is modest. After synthesizing the data results, it can be concluded that the plate fracture toughness of thickness of $30 \mathrm{~mm}$ is better.

After further analysis, it can be found that the experimental data of fracture toughness of 2124 alloy plates are concentrated, which indicate that the performance of the alloy plate is stable. Though the alloy fracture toughness with same direction is influenced a little with the variation of plate thickness, the overall variation is not evident. However, the plate fracture toughness values of same thickness with different orientation are distinct, and it appears obvious anisotropy. The plate fracture toughness of L-T orientation of thickness of $40 \mathrm{~mm}$ is higher about $9 \mathrm{MPa} \cdot \mathrm{m}^{1 / 2}$ than the $\mathrm{T}-\mathrm{L}$ orientation among them. 
The plate fracture toughness specimen of thickness of $30 \mathrm{~mm}$ was selected as observing object, the fracture morphology of L-T orientation and T-L orientation were observed by SEM separately, and the results are shown in figure 1.

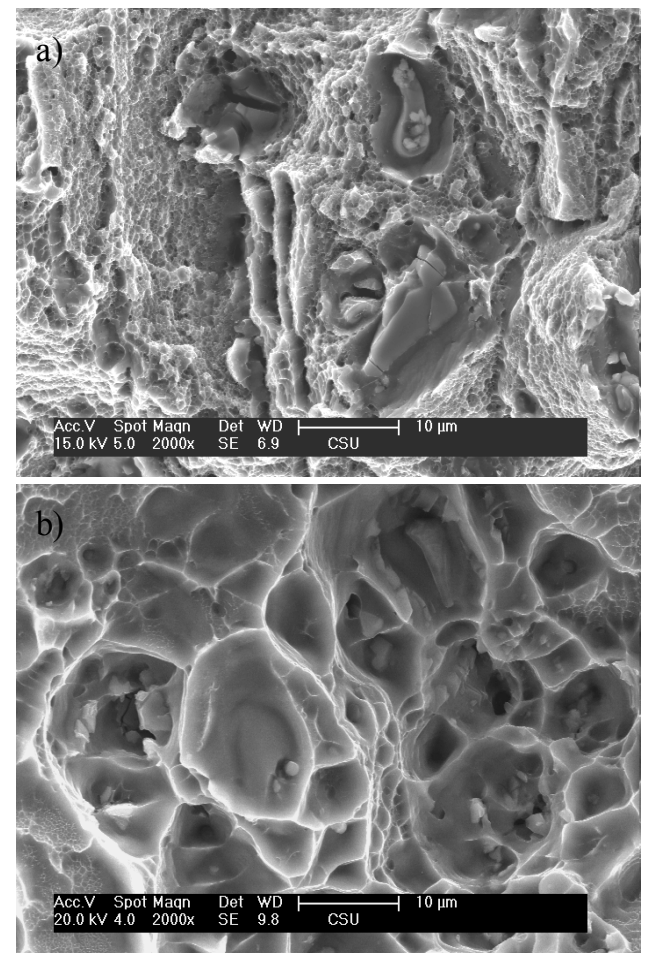

Fig. 1 The fracture morphology of fracture toughness specimen of different orientation

a) the orientation of L-T; b) the orientation of T-L

Compared to fracture morphology of T-L orientation and L-T orientation, it can be seen that the arrangement of cavities on the fracture of T-L orientation has obvious directivity along the rolling direction, namely the L orientation. The arrangement of cavities on the fracture of L-T orientation has no directivity, the ratio of transgranular cracking on fracture is big, and cavities are large and deep. Moreover, big cavities usually contain several small cavities. This is because after hot rolling, grains in alloy plate generally elongate along the deformation direction. Under the function of the grain shape and grain boundary characteristics, mechanical axis through density of grain boundaries is different with different orientation loading. The crack propagation direction of T-L orientation is same to the direction of the rolling deformation, so cavities whose direction is same to the grain deformation on fracture are left behind. Crack propagation direction of L-T orientation is perpendicular to the direction of rolling deformation, the extension resistance is big, so the cracks are easy to deviate towards the direction of small resistance (rolling direction), and the directivity of cavities arrangement is not obvious. At the same time, the encountered resistance is big when the crack propagation direction is perpendicular to the rolling deformation, the needed energy is high, and cracks absorb more energy when they propagate towards the L-T orientation, so the fracture toughness of L-T orientation is higher than the $\mathrm{T}$ - $\mathrm{L}$ orientation.

\section{Conclusions}

1) The plate thickness has some certain influences to the fracture toughness of 2124 alloy. Plate fracture toughness of L-T orientation of thickness of $40 \mathrm{~mm}$ is best, and plate fracture toughness value of T-L orientation of thickness of $55 \mathrm{~mm}$ is highest. But as a whole, the plate fracture toughness of thickness of $30 \mathrm{~mm}$ is better.

2) The fracture toughness $\mathrm{K}_{\mathrm{IC}}$ of 2124-T851 aluminum alloy plates has obvious anisotropy, $\mathrm{K}_{\mathrm{IC}}$ value of the $\mathrm{L}-\mathrm{T}$ orientation is relatively higher about $4 \sim 9 \mathrm{MPa} \cdot \mathrm{m}^{1 / 2}$ than the $\mathrm{T}-\mathrm{L}$ orientation. 


\section{Acknowledgements}

This work was financially supported by the National Science Foundation of China (51301065) and Natural Science Foundation of Hunan Province (14JJ7067).

\section{References}

[1] S.C. Wang, M.J. Starink, N. Gao, Int Mater. Rev.50(2005) 193-215.

[2] R N Lumley, I J Polmear, Scripta Mater. 50(2004) 1227-1231.

[3] M. L. Li, C. X. Chu, C. L. Xu, Light Alloy Fabrication Technol. 19(1991) 20-25.(in Chinese)

[4] N E Prasad, S V Kamat, K S Prasad, Eng. Frac. Mech. 46(1993) 209-223.

[5] Z.H. Liang, J. Nat. Sci. Heilongjiang Univ. 12(1996) 72-76.

[6] A. L. Ning, Heat Treat. Met. 29(2004) 13-16.

[7] Z Y Ma, S C Tjong, Compos. Sci. Technol. 59(1999) 737-747.

[8] R Lapovok, C Loader, F H Dalla Torre, Mater.Sci. Eng. 425(2006) 36-46.

[9] G. W. Smith, Thermochinica Acta 317(1998) 7-23. 